\title{
Quantitative genetics of life-history and morphology in a rare plant, Senecio integrifolius
}

\author{
BJÖRN WIDÉN \& STEFAN ANDERSSON \\ Department of Systematic Botany, University of Lund, Ö. Vallgatan 18-20, S-223 61 Lund, Sweden
}

\begin{abstract}
A paternal half-sib analysis was performed to estimate the narrow-sense heritability for 35 morphological and life-history characters in two populations of Senecio integrifolius, a rare and threatened plant in Sweden. The two populations differed greatly in size, the small one consisting of separate patches and the large one having a more or less continuous distribution. In addition to significant population differences in the mean of 26 characters, we found slightly higher heritabilities in the small and patchy population (average 0.49 ) than in the large and continuous population (average 0.43 ). Overall, the small population displayed significant additive genetic variation for a larger number of characters than the large population (19 vs. 14). Paternal (genetic) effects were consistent in two different environments; the ranking of sire means was similar despite a drastic reduction in light intensity, and few characters had a significant sire $\times$ environment interaction. Genetic correlations were also found between different characters measured in the same environment, although most of these were in the 'favourable' direction. Population differences in genetic parameters may reflect contrasting selection regimens at the two sites, although genetic drift may also be important. That more genetic variability was detected in the small population where plants occur in small and isolated patches indicates that the spatial structure has great effects on the retention of heritable variation, and that demographic and environmental factors are more important in the long-term survival of S. integrifolius. This is the first study that relates quantitative genetic variation to population size in a rare and threatened plant.
\end{abstract}

Keywords: conservation biology, heritability, paternal effects, rarity, Senecio integrifolius.

\section{Introduction}

Many plant species occur in small and isolated populations owing to the increasing fragmentation of their habitats. Given that stochastic factors reduce the genetic diversity when the number of individuals is small (Falconer, 1981), declining populations may have a greater risk of extinction in a changing environment than historically large populations (Avery \& Hill, 1977; Lande, 1980). Unfortunately, few attempts have been made to examine this idea in natural populations, and little is known about the relative importance of genetic and ecological factors in the long-term survival of species. Rare or endangered species are ideal model organisms for studies of extinction processes because most of their populations have remained small and isolated for a long time.

The population size necessary to maintain genetic variation following a bottleneck is much greater for single-locus characters than for characters governed by a large number of loci (Lande \& Barrowclough, 1987). Hence, a population may be genetically fixed at isozyme loci, yet contain substantial amounts of genetic variation for morphology and life-history, including traits closely related to fitness (Giles \& Edwards, 1983). Although heritable variations can be maintained by spatially or temporally varying selection (Ennos, 1983), particularly if there is genotype $\times$ environment interaction (Via \& Lande, 1985), natural selection is often expected to eliminate heritable variation for adaptive quantitative characters (Fisher, 1930; Falconer, 1981). Hence, the genetic variation necessary for long-term survival of a population in a changing environment may be more strongly influenced by past and current patterns of selection than by drastic reductions in population size. Genetic tradeoffs among characters with opposite effects on fitness could be a similar constraint on micro-evolution and the long- 
term maintenance of a population (Antonovics, 1976; Falconer, 1981; Rose \& Charlesworth, 1981; Roach, 1986). While the role of genetic diversity has become a major topic in conservation biology (Soulé \& Wilcox, 1980; Frankel \& Soulé, 1981; Schonewald-Cox et al., 1983; Lande \& Barrowclough, 1987), only a few studies have considered variation in quantitative characters (Meagher et al., 1978; Ouborg et al., 1991).

Although electrophoretic data provide accurate estimates of variation at individual loci, allowing comparisons within and among species (Karron, 1987; Waller et al., 1987; Karron et al., 1988; Hamrick \& Godt, 1989), only a quantitative genetic analysis can provide estimates of heritable variation directly available to selection. Provided that the genetic relationships among individuals can be manipulated, it is relatively straightforward to estimate the heritability and the extent to which different characters are genetically correlated (Falconer, 1981; Lawrence, 1984). The quantitative genetic approach is particularly useful if more than one population can be studied (Mitchell-Olds, 1986; Billington et al., 1988) and if individuals can be raised in more than one environment (Mazer \& Schick, 1991); genetic parameters are valid only for the population and environment in which they have been measured (Falconer, 1981; MitchellOlds \& Rutledge, 1986). The most reliable heritability estimates are those obtained in the field, but scientific or ethical reasons often prohibit experimental manipulation of populations of threatened species, making it necessary to use artificial environments.

Here we present a quantitative genetic study of two populations of Senecio integrifolius, a rare and threatened plant in Sweden, for which historical evidence indicates a more common occurrence in the past. We report heritabilities and genetic correlations for a wide range of characters and determine the extent to which the genetic architecture could represent a constraint on the long-term survival of remaining populations. Attempts are made to relate differences in quantitative genetic parameters to population structure, demographic parameters and the current selection regimen (Widén, 1987).

\section{Materials and methods}

\section{Materials}

Senecio integrifolius (L.) Clairv. (Asteraceae) is a Eurasian, diploid $(2 n=48)$, perennial herb restricted to calcareous pastures (Smith, 1979). Flowering occurs from late May to late June, but only a fraction of the plants flower in any given year (Widén, 1987). Most plants have a single stem with two to six flower heads arranged in a terminal corymb. Each head has tubular disc florets surrounded by ligulate ray florets. The florets develop into one-seeded indehiscent winddispersed fruits (termed 'seeds' in this paper), provided that they have been cross-pollinated; $S$. integrifolius is self-incompatible (Widén, 1991b) and pollinated by syrphids and other flies (Widén, unpublished data). Demographic data provide no evidence for a seed bank (Widén, 1987).

While $\sim 40$ localities have been reported in the southernmost province of Sweden (Skåne), only eight populations are currently known and some of these are rapidly diminishing in size (Nilsson \& Gustafsson, 1977). The decline is largely attributed to habitat destruction (use of fertilizer, absence of grazing, etc.; Widén, 1987).

Two contrasting populations were examined in this study. In the first population (Benestad, SE Skane), the plants occur in small patches (1-50 plants per patch) on dry ridges created by the eroding water in an open pasture on a slope of calcareous tufa (Regnéll, 1976). The relatively small population (average 130 flowering plants per year, range 30 to 250 plants) covers an area of $20 \times 200 \mathrm{~m}$, where individual patches are isolated by distances of 10-50 m. Heavy grazing by cattle reduces seed production, but has a beneficial effect on seedling establishment; trampling enhances germination by creating a large number of sites with open soil (Widén, 1987). The second population (Grödby, NE Skåne) covers a larger area $(300 \times 300 \mathrm{~m})$ and has a larger number of plants (average 1260 flowering plants per year, range $100-3000$ plants) than the Benestad population and is more or less continuous. The Grödby population was probably larger before 1960 when two-thirds of the locality was planted with Scots Pine (Pinus sylvestris). Most of the stems escape grazing owing to a low grazing pressure and the presence of shrubs (Juniperus, Rosa). Seedling establishment is hampered by a dense grass cover with few sites available for seed germination (Widén, 1987). Available data indicate that current differences between the Benestad and Grödby population have persisted for a long time (Regnéll, 1976; Nilsson \& Gustafsson, 1977).

\section{Methods}

In 1984 (Grödby) and 1985 (Benestad), one of us (B.W.) collected seeds from most of the plants that escaped grazing in these years $(n=420$ and $n=20$, respectively). Following germination in pots, four seedlings from each parent were planted individually in an experimental garden. In the spring of 1988, we transferred a large number of plants to an adjacent greenhouse to synchronize flowering prior to a crossing 
experiment. We used a nested mating design where each pollen donor ( 30 per population) was mated to two randomly selected (non-sib) plants acting as seed parents. Hence, each offspring could be assigned to a maternal full-sib family ('dam') and a paternal half-sib family ('sire'). The small number of plants sampled in the Benestad population made it necessary to use more than one pollen or seed parent from the maternal families representing this population. Following germination in petri dishes in July 1988, we planted $\sim 20$ seedlings from each cross (dam) in pots and randomized the pots in an unheated greenhouse. Prior to flowering in May 1989, we transferred all plants to the garden. In March 1990, the plants were randomly assigned to two greenhouse environments: (i) exposed to full daylight and (ii) shaded by a plastic net $(\sim 50$ per cent reduction in light intensity). This procedure provided an opportunity to examine the extent to which genetic parameters were consistent between different light regimens; shading by shrubs is an important environmental factor in present-day populations of $S$. integrifolius, particularly in the Grödby population (Widén, 1991a).

In addition to two binary characters scored in the first year (survival and propensity to flower), we scored each plant for a wide range of quantitative characters, all of which represent critical aspects of the life-cycle (Table 1).

\section{Data analysis}

For characters measured in single environments, we used the NESTED procedure in the SAS (1985) package to decompose the total phenotypic variance into variance from sire $\left(V_{\mathrm{S}}\right)$, dam within sire $\left(V_{\mathrm{D}(\mathrm{S})}\right)$, and plant within dam $\left(V_{\mathrm{w}}\right)$. A significant variance component from the sire indicates a genetic contribution from the pollen donor in addition to the genetic and non-genetic influence of the seed parent and estimates $1 / 4$ of the narrow sense heritability $\left(h^{2}\right)$, without con-

Table 1 Description of characters measured in this study. Numbers in abbreviations refer to the years in which the character was measured, while numbers in parentheses are sample sizes (if $n>1$ ). Flower and seed measurement refer to the terminal head. Percentage seed set was determined by crossing the terminal head with pollen from two adjacent plants

\begin{tabular}{|c|c|c|}
\hline Abbreviation/year & Description & Unit \\
\hline DIASEPT88 & Diameter of leaf rosette in September & $\mathrm{cm}$ \\
\hline DIADEC88 & Diameter of leaf rosette in December & $\mathrm{cm}$ \\
\hline LEAFLEN89 & Maximum leaf length in October & $\mathrm{cm}$ \\
\hline FLOWDAT 89,90 & No. of days from 1 April to first flowering & - \\
\hline HEIGHT 89,90 & Stem height & $\mathrm{cm}$ \\
\hline NODNUM90 & No. of nodes on main stem & - \\
\hline HEADSTEM 89,90 & $\log$ (no. of heads on main stem) & - \\
\hline HEADPLANT90 & $\log$ (no. of heads per plant) & - \\
\hline FLORNUM89,90 & No. of florets per head & - \\
\hline RAYNUM90 & $\log$ (no. of ray florets per head) & - \\
\hline INVOLUC89 & Involucre length & $\mathrm{mm}$ \\
\hline LIGLEN89,90 & Ligule length (3) & $\mathrm{mm}$ \\
\hline LIGWID 89,90 & Ligule width $(3)$ & $\mathrm{mm}$ \\
\hline LIGSHAPE 89,90 & Ligule length-width ratio (3) & - \\
\hline TUBLEN90 & Corolla tube length $(3)$ & $\mathrm{mm}$ \\
\hline STYLEN90 & Style length $(3)$ & $\mathrm{mm}$ \\
\hline STYLEXS 90 & Stylar exsertion (3) & $\mathrm{mm}$ \\
\hline SEEDSET90 & Arcsine (seeds/ovule) & $\%$ \\
\hline FRUITDAT90 & No. of days from 1 April to first seed dispersal & - \\
\hline DISPERS90 & No. of days from flowering to seed dispersal & - \\
\hline SEEDLEN89,90 & Seed length $(3)$ & $\mathrm{mm}$ \\
\hline SEEDWIG90 & Seed width (3) & $\mathrm{mm}$ \\
\hline SEEDWE1G90 & Seed weight $(5)$ & $10^{-5} \mathrm{~g}$ \\
\hline PAPPUS89,90 & Pappus length (3) & $\mathrm{mm}$ \\
\hline GERM90 & Arcsine (prop. germinable seeds) (25) & $\%$ \\
\hline MGT90 & No. of days to germination $(1-25)$ & - \\
\hline
\end{tabular}


founding effects of non-additive and non-genetic effects (Falconer, 1981; Lawrence, 1984; MitchellOlds \& Rutledge, 1986). An independent measure of the paternal (genetic) influence on the flowering date was obtained by calculating the product-moment correlation between the value for the paternal parent and the mean of its offspring (averaged across dam means). The conventional regression approach (Falconer, 1981) was avoided as the parent and offspring generations were raised in different environments. Differences among sires in first-year survival and flowering were examined by means of chi-square tests (data pooled across dams).

For characters measured in two environments (year 2), we used a nested factorial ANOVA with light regimens as a fixed effect and family identity (sire and dam nested within sire) as random effects. The GLM procedure (SAS, 1985) was employed to decompose the total phenotypic variance into variance among sires $\left(V_{\mathrm{S}}\right)$, between dams within sires $\left(V_{\mathrm{D}(\mathrm{S})}\right)$, among offspring within dams $\left(V_{\mathrm{W}}\right)$, the overall response to shade $\left(V_{\mathrm{E}}\right)$ and the extent to which sires $\left(V_{\mathrm{S} \times \mathrm{E}}\right)$ and dams $\left(V_{\mathrm{D}(\mathrm{S}) \times \mathrm{E}}\right)$ differed in their response to shade. Tests of significance followed recommendations by Winer (1971).

For characters which differed significantly among sires at a conservative level $(P<0.01)$, we used the Pearson correlation coefficient of sire means (averaged across dam means) to determine the extent to which pairs of characters were affected by the same genes (pleiotropy) or by different genes in linkage disequilibrium (Falconer, 1981). Paternal family-mean correlations are not confounded by non-genetic effects but may include a within-family component (Via, 1984; Roach, 1986; Weis et al., 1987). A similar analysis was performed for the same character expressed in two different environments; a high positive correlation indicates that sires retain their rank across environments due to genetic factors acting in the same direction irrespective of growth conditions (Via \& Lande, 1985).

\section{Assumptions}

Mitchell-Olds and Rutledge (1986) reviewed the basic assumptions of quantitative genetic analyses. In the present study, we assume disomic inheritance (Nordenstam, 1977), no inbreeding or assortative mating (random crosses between parents from different maternal families) and no genotype-environment correlation or competition between relatives (randomization of offspring across blocks and environments). However, we cannot exclude linkage disequilibrium, epistasis, etc.

\section{Results}

\section{Population differences}

There was no significant difference in seedling survivorship between the two populations (74.6 per cent and 78.9 per cent for the Benestad and Grödby populations, respectively; $P>0.05$, chi-square test), nor was there any difference in the propensity to flower in the first summer (57.6 and 57.7 per cent, respectively; $P>0.05$; chi-square test). However, the two populations differed in a wide range of quantitative characters (Table 2). Plants from the Benestad population flowered later in the summer (FLOWDAT89,90) and had taller stems (HEIGHT89,90), fewer heads per stem (HEADSTEM89,90), fewer florets per head (FLORNUM89,90), shorter and relatively wider ligules (LIGLEN90, LIGSHAPE90), longer styles (STYLEN90), larger seeds (SEEDLEN90, SEEDWID90, SEEDWEIG90), a smaller pappus (PAPPUS89,90) and slower germination (MGT90) than plants from the Grödby population.

\section{Genetic variation within populations}

Low crossability and germinability in some families reduced the number of sires to 22 for the Benestad population and 20 for the Grödby population. While plants with different sires had similar rates of survival in the first year $(P>0.05)$, we detected significant variation among sires in the frequency of plants that flowered in their first summer $\left(\chi^{2}{ }_{21}=38.50, P=0.012\right.$ for Benestad and $\chi^{2}{ }_{19}=38.45, P=0.005$ for Grödby $)$.

For quantitative characters measured in the first year, there was a significant sire-component for six characters in the Benestad population and four characters in the Grödby population (Table 3). Apart from rosette diameter (DIASEPT), seed length (SEEDLEN) and ligule shape (LIGSHAPE) which differed significantly among sires in both populations, the Benestad population also possessed significant among-sire variation for date of first flowering (FLOWDAT), stem height (HEIGHT) and pappus size (PAPPUS), while the Grödby population had sires which differed significantly in leaf length (LEAFLEN).

In the second year, there was a significant amongsire component for 13 characters in the Benestad population and 10 characters in the Grödby population (Table 4). Flowering date (FLOWDAT), the number of florets per head (FLORNUM), date of first fruiting (FRUITDAT), seed length (SEEDLEN) and pappus size (PAPPUs) differed significantly among sires in both populations. For plants representing the Benestad population, we also detected among-sire variation in stem height (HEIGHT), style length (STYLEN) stylar exsertion (STY- 
Table 2 Means and s.d.s for quantitative characters. Sample sizes for individual traits pooled across paternal families, blocks and environments varies between 364 and 387 in 1988 and 1989. For characters measured in 1990 , $n=644-667$ for plants derived from Benestad and $n=587-593$ for Grödby plants

\begin{tabular}{|c|c|c|c|c|c|}
\hline \multirow[b]{2}{*}{ Character } & \multicolumn{2}{|c|}{ Benestad } & \multicolumn{2}{|l|}{ Grödby } & \multirow[b]{2}{*}{$F$-ratio } \\
\hline & Mean & s.d. & Mean & s.d. & \\
\hline DIASEPT88 & 6.6 & 3.14 & 6.7 & 3.17 & 0.20 \\
\hline DIADEC88 & 12.8 & 3.79 & 13.5 & 4.02 & $5.46^{*}$ \\
\hline LEAFLEN89 & 9.4 & 1.98 & 9.1 & 1.98 & $4.41^{*}$ \\
\hline FLOWDAT89 & 48.3 & 3.62 & 45.1 & 3.94 & $139.0^{* * *}$ \\
\hline FLOWDAT90 & 26.4 & 5.73 & 22.6 & 5.63 & $138.9^{* * *}$ \\
\hline HEIGHT89 & 18.6 & 4.57 & 16.3 & 4.29 & $50.2^{* * *}$ \\
\hline HEIGHT90 & 34.4 & 8.90 & 30.4 & 8.02 & $75.02 * * *$ \\
\hline NODNUM90 & 8.3 & 2.31 & 8.2 & 2.30 & 1.15 \\
\hline HEADSTEM 89 & 4.3 & 1.83 & 5.0 & 2.32 & $20.5^{* * *}$ \\
\hline HEADSTEM90 & 5.0 & 1.97 & 5.7 & 2.10 & $33.0^{* * *}$ \\
\hline HEADPLANT 90 & 7.2 & 3.14 & 7.4 & 2.97 & 1.78 \\
\hline FLORNUM89 & 97.9 & 16.4 & 105.0 & 18.7 & $27.7^{* * *}$ \\
\hline FLORNUM90 & 88.4 & 16.98 & 96.3 & 19.57 & $58.18^{* * *}$ \\
\hline RAYNUM90 & 14.7 & 2.48 & 15.4 & 2.87 & $22.34 * * *$ \\
\hline INVOLUC89 & 6.08 & 0.674 & 6.17 & 0.684 & 3.16 \\
\hline LIGLEN89 & 8.8 & 1.34 & 8.8 & 1.48 & 0.100 \\
\hline LIGLEN90 & 11.3 & 1.83 & 12.2 & 1.97 & $63.77^{* * *}$ \\
\hline LIGWID89 & 3.01 & 0.47 & 2.94 & 0.39 & $4.33^{*}$ \\
\hline LIGWID90 & 3.81 & 0.50 & 3.81 & 0.55 & 0.08 \\
\hline LIGSHAPE89 & 3.0 & 0.59 & 3.0 & 0.60 & 0.56 \\
\hline LIGSHAPE90 & 3.0 & 0.61 & 3.3 & 0.67 & $40.4^{* * *}$ \\
\hline TUBLEN90 & 3.27 & 0.56 & 3.17 & 0.66 & $9.21 * *$ \\
\hline STYLEN90 & 4.33 & 0.49 & 4.21 & 0.48 & $19.64^{* * *}$ \\
\hline STYLEXS90 & 1.06 & 0.53 & 1.04 & 0.58 & 0.29 \\
\hline SEEDSET90 & 0.524 & 0.238 & 0.455 & 0.212 & $34.07^{* * *}$ \\
\hline FRUITDAT90 & 52.2 & 5.85 & 50.5 & 5.31 & $28.2^{* * *}$ \\
\hline DISPERS90 & 25.8 & 2.15 & 27.8 & 2.44 & $253.0^{* * *}$ \\
\hline SEEDLEN89 & 2.50 & 0.46 & 2.50 & 0.36 & 0.018 \\
\hline SEEDLEN90 & 3.61 & 0.42 & 3.52 & 0.42 & $14.76^{* * *}$ \\
\hline SEEDWID90 & 0.93 & 0.09 & 0.87 & 0.08 & $144.80^{* * *}$ \\
\hline SEEDWEIG90 & 75.1 & 14.20 & 64.1 & 10.36 & $235.84^{* * *}$ \\
\hline PAPPUS89 & 6.12 & 1.26 & 6.56 & 1.23 & $23.9^{* * *}$ \\
\hline PAPPUS90 & 6.25 & 1.38 & 6.56 & 1.37 & $15.29^{* * *}$ \\
\hline GERM90 & 0.949 & 0.097 & 0.957 & 70.087 & $3.97^{*}$ \\
\hline MGT90 & 12.7 & 1.63 & 12.1 & 1.53 & $51.89^{* * *}$ \\
\hline
\end{tabular}

The $F$-ratio refers to a comparison of the two populations (ANOVA).

${ }^{*} P<0.05,{ }^{* *} P<0.01,{ }^{* * *} P<0.001$.

LEXS), seed set (SEEDSET), the number of days from flowering to seed dispersal (DISPERS), seed size (SEEDWID, SEEDWEIG) and germination rate (MGT), while the Grödby population had sires with different node number (NODNUM), head number (HEADSTEM, HEADPLANT), ray floret number (RAYNUM) and ligule length (LIGLEN). We failed to detect significant variation among sires in their response to shade (no sire $\times$ environment interaction) in most characters for which significant amounts of among-sire variance were detected (Table 4), so we averaged the heritabilities $\left(h^{2}\right)$ for the two environments (Table 5). Despite large standard errors (as indicated by several values $>1$; Tables 3 and 5), there was a tendency for the Benestad population to have higher heritabilities (average 0.49 , range 0.21 to 1.20 ) than the Grödby population (average 0.43 , range 0.15 to 1.03 ). That the heritability for date of first flowering (FLowDAT ) was greater in the Benestad population than in the Grödby population (Tables 3 and 5) is consistent with results of the parent-offspring analysis which revealed a strong paternal influence on the flowering date in the Benestad population $(r>0.65, P<0.001)$ but not in the Grödby population $(r<0.45, P \geq 0.05)$.

\section{Environmental response}

Shaded plants were characterized by a taller stem (HEIGHT) with a larger number of nodes (NODNUM), later flowering (FLOWDAT), a larger number of florets per head (FLORNUM), longer ligules (LIGLEN, LIGSHAPE), delayed seed dispersal (FRUITDAT, DISPERS) and seeds with a more extended germination period (MGT), than plants exposed to full daylight (Table 6). The response was consistent among sires, the only exception being date of first flowering (FLOwDAT), ligule width (LIGwID) and number of days from flowering to seed dispersal (DISPERS) in the Grödby population (Table 4). However, the ranking of sire means was highly consistent in the two environments (Table 6); a sire with a large value in daylight usually had a large value in shade (and vice versa). The sires also retained their ranks between environments used in different years (Table 7). Between-year correlations were slightly larger in the Benestad population $(r=0.75)$ than in the Grödby population $(r=0.64)$.

\section{Genetic correlations among characters}

In the first year, we found a positive relationship between rosette and leaf size (DIASEPT, LEAFLEN) in the Grödby population $(r=0.633, P<0.01)$ and a tendency for early-flowering families (FLOWDAT) in the Benestad population to have longer seeds (SEEDLEN) and a larger pappus (PAPPUS), two positively correlated characters $(r=0.668, P<0.01)$, than late-flowering families $(r<-0.80, P<0.001)$. A larger number of genetic correlations was detected in the second year, most of which were consistent across environments (Table 8). In the Benestad population, we detected strong positive correlations between date of first flowering (FLOWDAT) and seed dispersal (FRUITDAT) and 
Table 3 Percentage of variance from sire $\left(V_{\mathrm{S}}\right)$, dam within sire $\left(V_{\mathrm{D}}\right)$ and plant within dam $\left(V_{\mathrm{W}}\right)$ for characters measured in the first year (nested ANOVA $)$. The narrow sense heritability, calculated as $h^{2}=4 V_{\mathrm{S}} /\left(V_{\mathrm{S}}+V_{\mathrm{D}}+V_{\mathrm{w}}\right)$, is also given. The average number of offspring per dam was 8.9 for Benestad ( 22 sires) and 9.8 for Grödby (20 sires)

\begin{tabular}{|c|c|c|c|c|c|c|c|c|}
\hline \multirow[b]{2}{*}{ Character } & \multicolumn{4}{|c|}{ Benestad } & \multicolumn{4}{|l|}{ Grödby } \\
\hline & $V_{\mathrm{S}}$ & $V_{\mathrm{D}}$ & $V_{\mathrm{W}}$ & $h^{2}$ & $V_{\mathrm{s}}$ & $V_{\mathrm{D}}$ & $V_{\mathrm{w}}$ & $h^{2}$ \\
\hline DIASEPT & $5.9^{*}$ & 0.0 & 94.1 & 0.22 & $11.8^{* * *}$ & 2.0 & 86.2 & 0.47 \\
\hline DIADEC & 1.0 & 1.6 & 97.4 & 0.04 & 5.3 & 0.8 & 93.6 & 0.21 \\
\hline LEAFLEN & 0.0 & 6.9 & 93.1 & 0.00 & $8.8^{*}$ & 2.2 & 89.0 & 0.35 \\
\hline FLOWDAT & $32.7^{* * * * * *}$ & 9.1 & 58.2 & 1.26 & 11.8 & 18.8 & 69.4 & 0.47 \\
\hline HEIGHT & $14.6^{* *}$ & 3.9 & 81.5 & 0.56 & 2.7 & 4.3 & 93.0 & 0.11 \\
\hline HEADSTEM & 1.0 & 5.7 & 93.3 & 0.04 & 3.0 & 10.5 & 86.5 & 0.12 \\
\hline FLORNUM & 3.0 & 19.4 & 87.6 & 0.12 & 19.0 & 8.8 & 72.2 & 0.76 \\
\hline INVOLUC & 9.3 & 12.6 & 78.1 & 0.37 & 3.2 & 10.6 & 86.2 & 0.13 \\
\hline LIGLEN & 2.8 & 20.2 & 77.0 & 0.11 & 10.6 & 12.8 & 76.6 & 0.42 \\
\hline LIGWID & 6.7 & 19.4 & 73.9 & 0.27 & 6.6 & 14.3 & 79.1 & 0.26 \\
\hline LIGSHAPE & $14.5^{*}$ & 20.8 & 64.7 & 0.65 & $16.1^{*}$ & 8.6 & 74.3 & 0.64 \\
\hline SEEDLEN & $25.7^{* * *}$ & 4.1 & 70.2 & 0.99 & $15.5^{* *}$ & 3.4 & 81.1 & 0.62 \\
\hline PAPPUS & $18.0^{* *}$ & 6.8 & 75.3 & 0.71 & 0.0 & 13.1 & 86.9 & 0.00 \\
\hline
\end{tabular}

${ }^{*} P<0.05,{ }^{* *} P<0.01,{ }^{* * *} P<0.001$.

Table 4 Significance of variance components ( $F$-values) in a nested factorial ANOVA of characters measured in the second year. The among-sire component $\left(V_{S}\right)$ was tested as $M S_{\mathrm{S}} / M S_{\mathrm{D}(\mathrm{S})}$, the environment component $\left(V_{\mathrm{E}}\right)$ as $M S_{\mathrm{E}} / M S_{\mathrm{S}}$ and the sire $\times$ environment interaction $\left(V_{\mathrm{S} \times \mathrm{E}}\right)$ as $M S_{\mathrm{S} \times \mathrm{E}} / M S_{\mathrm{D}(\mathrm{S}) \times \mathrm{E}}$

\begin{tabular}{|c|c|c|c|c|c|c|}
\hline \multirow[b]{2}{*}{ Character } & \multicolumn{3}{|c|}{ Benestad (22 sires) } & \multicolumn{3}{|c|}{ Grödby (20 sires) } \\
\hline & Sire $(\mathbf{S})$ & $\operatorname{Env}(E)$ & $S \times E$ & Sire & $\operatorname{Env}(E)$ & $\mathrm{S} \times \mathrm{E}$ \\
\hline FLOWDAT & $8.27^{* * *}$ & $250.21^{* * *}$ & 0.77 & $2.65^{*}$ & $98.50^{* * *}$ & $2.70^{*}$ \\
\hline HEIGHT & $6.18^{* * *}$ & $608.43^{* * *}$ & 1.17 & 1.69 & $457.15^{* * *}$ & 1.18 \\
\hline NODNUM & 1.53 & $19.27^{* * *}$ & 1.14 & $4.31^{* * *}$ & $17.61^{* * *}$ & 0.70 \\
\hline HEADSTEM & 1.88 & 0.01 & 0.51 & $2.48^{*}$ & $4.45^{*}$ & 1.69 \\
\hline HEADPLANT & 1.60 & 0.77 & 0.98 & $2.33^{*}$ & 1.03 & 0.95 \\
\hline FLORNUM & $2.20^{*}$ & $7.70^{*}$ & 1.64 & $2.85^{* *}$ & $15.34^{* * *}$ & 0.56 \\
\hline RAYNUM & 0.86 & 1.58 & 1.14 & $4.08^{* * *}$ & 3.40 & 1.59 \\
\hline LIGLEN & 1.18 & $40.27^{* * *}$ & 0.79 & $2.27^{*}$ & $155.95^{* * * *}$ & 0.63 \\
\hline LIGWID & 1.71 & 1.66 & 1.30 & 0.99 & 0.06 & $2.28^{*}$ \\
\hline LIGSHAPE & 1.72 & $26.30^{* * *}$ & 1.52 & 1.97 & $60.06^{* * *}$ & 1.25 \\
\hline TUBLEN & 1.30 & $7.26^{*}$ & 1.29 & 1.87 & 1.59 & 1.03 \\
\hline STYLEN & $2.18^{*}$ & 0.45 & 0.97 & 1.17 & $6.31^{*}$ & 1.03 \\
\hline STYLEXS & $2.99^{* *}$ & 3.08 & 1.38 & 1.57 & 2.22 & 0.42 \\
\hline SEEDSET & $2.16^{*}$ & 2.53 & 1.34 & 1.92 & $9.80^{* *}$ & 1.70 \\
\hline FRUITDAT & $6.35^{* * *}$ & $326.22 * * *$ & 0.97 & $3.03^{* *}$ & $206.33^{* * *}$ & 1.91 \\
\hline DISPERS & $2.18^{*}$ & $43.32^{* * *}$ & 0.36 & 1.58 & $11.94^{* *}$ & $3.28^{* *}$ \\
\hline SEEDLEN & $2.52^{*}$ & 0.45 & 2.03 & $4.58^{* * *}$ & $8.63^{* *}$ & 1.38 \\
\hline SEEDWID & $3.53^{* *}$ & 0.05 & 0.79 & 1.70 & 3.02 & 1.04 \\
\hline SEEDWEIG & $6.81^{* * *}$ & 0.00 & 0.91 & 1.15 & 1.12 & 1.10 \\
\hline PAPPUS & $2.24^{*}$ & 1.09 & 0.92 & $3.36^{* *}$ & 1.35 & 1.66 \\
\hline MGT & $2.44^{*}$ & $15.71^{* * *}$ & 0.77 & 1.54 & $10.65^{* *}$ & 1.30 \\
\hline
\end{tabular}

${ }^{*} P<0.05,{ }^{* *} P<0.01,{ }^{* * *} P<0.001$. 
Table 5 Narrow sense heritabilities $\left(h^{2}\right)$ for characters measured in the second year (the number of sires is 22 for Benestad and 20 for Grödby). Significance levels refer to $F$-tests of the sire mean square in nested ANOVA (daylight, shade) and in nested factorial ANOVA (average, see Table 4). The average number of plants per dam $(n)$ is also given

\begin{tabular}{|c|c|c|c|c|c|c|}
\hline \multirow[b]{2}{*}{ Character } & \multicolumn{3}{|l|}{ Benestad } & \multicolumn{3}{|l|}{ Grödby } \\
\hline & Daylight & Shade & Average & Daylight & Shade & Average \\
\hline FLOWDAT & $1.08^{* * *}$ & $0.78^{* *}$ & $0.93^{* * *}$ & 0.19 & $0.70^{* *}$ & $0.44^{*}$ \\
\hline HEIGHT & $0.92^{* * *}$ & $0.57^{* *}$ & $0.75^{* * *}$ & $0.70^{* * *}$ & 0.02 & 0.36 \\
\hline NODNUM & 0.14 & 0.20 & 0.17 & $0.24 * *$ & $0.34^{*}$ & $0.29^{* * *}$ \\
\hline HEADSTEM & 0.05 & 0.26 & 0.16 & 0.13 & $0.44^{* *}$ & $0.29^{*}$ \\
\hline HEADPLANT & 0.21 & 0.20 & 0.21 & 0.09 & $0.22^{*}$ & $0.15^{*}$ \\
\hline FLORNUM & $0.51^{*}$ & $0.63^{*}$ & $0.57^{*}$ & $0.56^{*}$ & $0.48^{*}$ & $0.52^{* *}$ \\
\hline RAYNUM & 0.24 & 0.00 & 0.12 & $0.89^{* * *}$ & $0.71^{*}$ & $0.80^{\text {*** }}$ \\
\hline LIGLEN & 0.00 & $0.52^{*}$ & 0.26 & 0.24 & $0.64^{* *}$ & $0.44^{*}$ \\
\hline LIGWID & $0.72^{*}$ & 0.11 & 0.42 & 0.00 & 0.23 & 0.12 \\
\hline LIGSHAPE & $0.80^{*}$ & $0.63^{*}$ & 0.71 & 0.19 & $0.82^{* *}$ & 0.51 \\
\hline TUBLEN & 0.50 & 0.00 & 0.25 & 0.49 & $0.62^{*}$ & 0.55 \\
\hline STYLEN & 0.29 & $0.56^{*}$ & $0.42^{*}$ & 0.33 & 0.00 & 0.17 \\
\hline STYLEXS & $1.07^{* *}$ & $0.66^{*}$ & $0.86^{* *}$ & 0.26 & 0.27 & 0.27 \\
\hline SEEDSET & $0.42^{*}$ & 0.18 & $0.30^{*}$ & $0.28^{*}$ & 0.18 & 0.23 \\
\hline FRUITDAT & $1.07^{* * *}$ & $0.75^{* *}$ & $0.91^{* * * *}$ & 0.10 & $0.84 * *$ & $0.47^{* *}$ \\
\hline DISPERS & 0.16 & 0.26 & $0.21^{*}$ & $0.44^{*}$ & 0.09 & 0.27 \\
\hline SEEDLEN & $0.77^{*}$ & $0.97^{* *}$ & $0.87^{*}$ & $0.56^{*}$ & $1.50^{* * *}$ & $1.03^{* * *}$ \\
\hline SEEDWID & $1.15^{* * *}$ & 0.58 & $0.87^{* *}$ & 0.44 & 0.12 & 0.28 \\
\hline SEEDWEIG & $1.15^{* * *}$ & $1.25^{* * *}$ & $1.20^{* * *}$ & 0.13 & 0.00 & 0.07 \\
\hline PAPPUS & $0.75^{*}$ & 0.42 & $0.58^{*}$ & $0.89^{* *}$ & $0.98^{* *}$ & $0.93^{* *}$ \\
\hline MGT & $0.58^{* *}$ & $0.48^{*}$ & $0.53^{*}$ & 0.13 & 0.23 & 0.18 \\
\hline$n$ & 7.80 & 7.45 & & 7.53 & 7.24 & \\
\hline
\end{tabular}

${ }^{*} P<0.05,{ }^{* *} P<0.01,{ }^{* * *} P<0.001$.

between seed width (SEEDwID) and seed weight (sEEDWEIG) and a negative relationship between date of first flowering (FLOWDAT ) and seed size (SEEDWID, SEEDWEIG). In the Grödby population, there was a negative association between seed length (SEEDLEN) and pappus size (PAPPUS) and a tendency for the number of ray florets (RAYNUM) to increase with the number of florets (FLOWNUM), date of first seed dispersal (FRUITDAT), seed length (SEEDLEN) and pappus length (PAPPUS).

\section{Discussion}

The present study demonstrates heritable variation for a wide range of quantitative characters in a rare and threatened plant in Sweden. As our analysis involved paternal half-sib families, we assume that the heritabilities provide relatively 'clean' estimates of variation available to selection (Falconer, 1981; Mitchell-Olds \& Rutledge, 1986). The small number of characters with significant genotype by environment interaction revealed in the ANOvAs indicates that paternal genotypes responded in the same way and that heritabilities were of similar magnitude in the two environments. Correlation analyses confirmed that paternal genotypes retained their relative rank irrespective of growth conditions and also provide evidence for a paternal (genetic) influence on characters for which no narrow sense heritability could be detected. Hence, there should be a great potential for further adaptive change of the populations studied, provided that the characters are subject to selection (see below). The heritability values obtained are comparable in magnitude to those estimated in more common and widespread plants (Venable, 1984; Mitchell-Olds, 1986; Weis et al., 1987; Billington et al., 1988), suggesting that rarity may not be associated with low genetic variance. Given that present-day populations can be used to infer the genetic architecture of extinct populations, we suggest that genetic erosion has played a minor role in the recent decline of $S$. integrifolius in Sweden. Habitat destruction combined with demographic stochasticity in small and fragmented populations are probably more important factors, stressing the need of proper management recommendations based on detailed 
Table 6 Response to full daylight and shade (averaged across sires) and the correlation between sire means in the two environments ( $n=22$ and 20 for Benestad and Grödby, respectively). The means for traits with a significant environment component $(P<0.05$; Table 4$)$ are given in bold

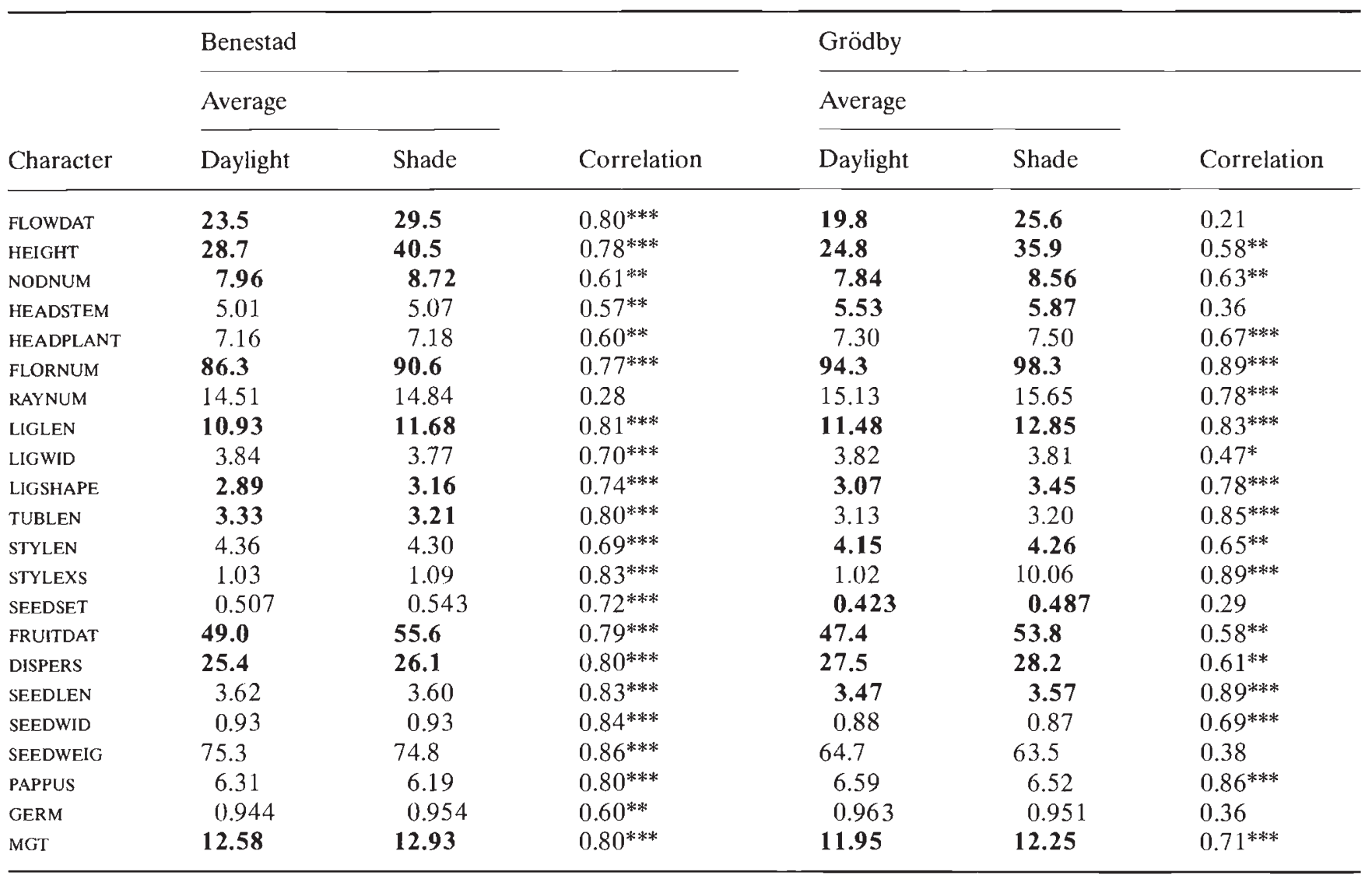

${ }^{*} P<0.05, * * P<0.01,{ }^{* * *} P<0.001$.

Table 7 Correlation coefficient of sire means in 2 years ( $n=22$ and 20 for Benestad and Grödby, respectively)

\begin{tabular}{llllll}
\hline & \multicolumn{2}{c}{ Benestad } & & \multicolumn{2}{c}{ Grödby } \\
\cline { 2 - 3 } \cline { 5 - 6 } Character & Daylight & Shade & & Daylight & Shade \\
\hline FLOWDAT & $0.81^{* * *}$ & $0.84^{* * * *}$ & & 0.37 & $0.65^{* * *}$ \\
HEIGHT & $0.80^{* * *}$ & $0.68^{* * *}$ & & $0.72^{* * *}$ & $0.47^{* *}$ \\
HEADSTEM & $0.44^{*}$ & $0.70^{* * *}$ & & 0.24 & $0.74^{* * *}$ \\
FLORNUM & $0.58^{* *}$ & $0.72^{* * *}$ & & $0.75^{* * *}$ & $0.71^{* * *}$ \\
LIGLEN & $0.83^{* * *}$ & $0.88^{* * *}$ & & $0.77^{* * *}$ & $0.60^{* *}$ \\
LIGWID & $0.64^{* *}$ & $0.64^{* *}$ & & $0.68^{* * *}$ & 0.38 \\
LIGSHAPE & $0.83^{* * *}$ & $0.88^{* * *}$ & & $0.68^{* * *}$ & 0.37 \\
SEEDLEN & $0.79^{* * *}$ & $0.69^{* * *}$ & & $0.77^{* * *}$ & $0.78^{* * * *}$ \\
PAPPUS & $0.76^{* * *}$ & $0.63^{* *}$ & & $0.51^{*}$ & $0.72^{* *}$ \\
\hline
\end{tabular}

${ }^{*} P<0.05,{ }^{* *} P<0.01,{ }^{* * *} P<0.001$.

knowledge of population dynamics (Widén, 1987; Lande, 1988).

Although our study did not include lifetime fitness, we assume that most of the characters have a strong impact on individual fitness. For example, on the basis of previous work on S. integrifolius (Widén, 1987, 1991a, 1993; unpublished data), there should be a selective advantage of having many large leaves (great competitive ability), a large number of many-flowered heads (high potential fecundity), early flowering and large attractive structures (high pollination efficiency), large seeds (vigorous seedlings) and a large pappus (efficient wind dispersal). These characters had significant amounts of additive variation in at least one population, a surprising result considering the low levels of variation expected for characters subject to selection (Fisher, 1930; Falconer, 1981; Price \& Schluter, 1991). It is important to stress that this and other studies demonstrating additive variation for fitness components (Venable, 1984; Mousseau \& Roff, 1987; Weis et al., 1987; Billington et al., 1988) were performed under controlled conditions, suggesting that heritabilities may have been overestimated (Falconer, 1981; Mitchell-Olds \& Rutledge, 1986). Studies performed in natural populations usually detect little or no additive genetic variance in morphology or life-history (e.g. 
Table 8 Sire means correlations measured in the second year. Values reported are for plants grown in daylight (above) and plants grown in shade (below; $n=22$ and 20 for Benestad and Grödby, respectively). Only characters that were significantly heritable $(P<0.01)$ were considered (see Tables 3 and 4$)$

\begin{tabular}{|c|c|c|c|c|c|}
\hline Character & 1 & 2 & 3 & 4 & 5 \\
\hline \multicolumn{6}{|l|}{ Benestad } \\
\hline 1 HEIGHT & . & & & & \\
\hline 2 FLOWDAT & $\begin{array}{l}-0.05 \\
-0.51^{*}\end{array}$ & . & & & \\
\hline 3 STYLEXC & $\begin{array}{l}-0.22 \\
-0.12\end{array}$ & $\begin{array}{r}0.16 \\
-0.32\end{array}$ & $\cdot$ & & \\
\hline 4 FRUITDAT & $\begin{array}{c}0.01 \\
-0.43^{*}\end{array}$ & $\begin{array}{l}0.97^{* * *} \\
0.96^{* * *}\end{array}$ & $\begin{array}{r}0.09 \\
-0.35\end{array}$ & . & \\
\hline 5 SEEDWID & $\begin{array}{l}0.21 \\
0.44^{*}\end{array}$ & $\begin{array}{l}-0.59^{* *} \\
-0.52^{*}\end{array}$ & $\begin{array}{r}-0.19 \\
0.05\end{array}$ & $\begin{array}{l}-0.48^{*} \\
-0.37\end{array}$ & • \\
\hline 6 SEEDWEIG & $\begin{array}{l}0.42^{*} \\
0.49^{*}\end{array}$ & $\begin{array}{l}-0.44^{*} \\
-0.41\end{array}$ & $\begin{array}{r}-0.04 \\
0.00\end{array}$ & $\begin{array}{l}-0.32 \\
-0.22\end{array}$ & $\begin{array}{l}0.85^{* * *} \\
0.86^{* * *}\end{array}$ \\
\hline \multicolumn{6}{|l|}{ Grödby } \\
\hline 1 NODNUM & $\cdot$ & & & & \\
\hline 2 RAYNUM & $\begin{array}{l}-0.38 \\
-0.18\end{array}$ & . & & & \\
\hline 3 FLOWNUM & $\begin{array}{l}-0.12 \\
-0.21\end{array}$ & $\begin{array}{l}0.67^{* *} \\
0.37\end{array}$ & . & & \\
\hline 4 FRUITDAT & $\begin{array}{l}0.01 \\
0.06\end{array}$ & $\begin{array}{l}-0.42 \\
-0.70^{* * *}\end{array}$ & $\begin{array}{l}-0.34 \\
-0.38\end{array}$ & . & \\
\hline 5 SEEDLEN & $\begin{array}{l}0.16 \\
0.08\end{array}$ & $\begin{array}{l}0.21 \\
0.62^{* *}\end{array}$ & $\begin{array}{r}-0.14 \\
0.03\end{array}$ & $\begin{array}{l}-0.37 \\
-0.41\end{array}$ & $\cdot$ \\
\hline 6 PAPPUS & $\begin{array}{l}-0.12 \\
-0.08\end{array}$ & $\begin{array}{c}0.00 \\
-0.44^{*}\end{array}$ & $\begin{array}{r}0.17 \\
-0.15\end{array}$ & $\begin{array}{l}0.27 \\
0.43\end{array}$ & $\begin{array}{l}-0.76^{* * *} \\
-0.62^{* *}\end{array}$ \\
\hline
\end{tabular}

Mitchell-Olds, 1986; Schwaegele \& Levin, 1991). However, for threatened species, it is necessary to obtain genetic data in artificial environments, given the ethical and scientific arguments against manipulations of natural populations. Moreover, in the present study, we found no evidence for consistent changes in genetic parameters between two contrasting light regimens, implying that the choice of environment may have little effect on the heritability.

In the following, we discuss possible mechanisms that may prevent the erosion of genetic variance in $S$. integrifolius and relate population differences in quantitative genetic parameters to current habitat conditions (Table 9). It may be difficult for selection to reduce genetic variation in a spatially heterogenous habitat if genotypes have different norms of reaction, i.e. if there is genotype $\times$ environment interaction. This hypothesis may be relevant in $S$. integrifolius because shading by shrubs results in considerable heterogeneity in some populations (Widén, 1991a). However, even though the light level had a strong effect on the overall character means, we failed to detect consistent differences among parental genotypes in their response to shade; the rank order of sire means changed little between the two environments. The positive correlation between the expression in different environments should facilitate rather than prevent the erosion of genetic variance, provided that selection act in the same direction irrespective of growth conditions (Via \& Lande, 1985). However, we cannot exclude the possibility that genotype $\times$ environment interaction exists for other environmental variables.

The retention of genetic variance can also be attributed to genetic correlations among characters with opposite effects on fitness (Antonovics, 1976; Falconer, 1981; Rose \& Charlesworth, 1981; Roach, 1986). However, based on hypotheses regarding selection pressures in populations of $S$. integrifolius (see above), it seems that the direction of selection and the sign of the correlation converge for most characters, paternal genotypes either had the favourable (or unfavourable) state for several characters simultaneously (see also Mitchell-Olds, 1986). A possible exception is the negative genetic relationship between 
Table 9 Demographic and genetic parameters for the two populations. Field data (means) are from Widén $(1987,1993$, unpublished), while narrow sense heritabilities $\left(h^{2}\right)$ and between-environment correlations $(r)$ are from the present study (Tables 3, 5,6 and 7). $n=$ the number of years in which the populations were studied

\begin{tabular}{lcc}
\hline Parameter & Benestad & Grödby \\
\cline { 1 - 2 } No. of flowering stems per year $(n=12)$ & 132 & 1258 \\
Proportion of ungrazed stems $(n=3)$ & 0.05 & 0.74 \\
Seed set $\%(n=3)$ & 42 & 75 \\
Seedlings as $\%$ of seed production $(n=2)$ & 75.2 & 8.4 \\
No. of characters with significant $h^{2}$ & 19 & 14 \\
Average $h^{2}$ & 0.49 & 0.43 \\
No. of characters with significant $r$ & 39 & 31 \\
Average $r$ & 0.75 & 0.64 \\
\hline
\end{tabular}

pappus and seed size in the Grödby population, which should prevent selection in favour of efficient dispersal (large pappus) and competitive seedlings (large seeds).

Fitness characters can remain heritable when the relationship between trait and fitness is obscured by factors unrelated to genotype, a hypothesis that could account for some of the genetic differences between the Grödby and Benestad populations. For example, selection for early flowering in the heavily grazed Benestad population may have a weak influence on the heritability if the risk of being grazed is independent of flowering time, perhaps explaining why a large amount of heritable variation has been retained for this character. A similar conclusion applies to plant height, degree of stylar exsertion, date of first seed dispersal, seed weight and the rate of seed germination, all of which exhibited more consistent heritabilities in the Benestad population than in the Grödby population.

Contrasting environmental conditions may also explain population differences in the heritability for characters influencing seedling fitness. The high probability that a seed produces a seedling in the Benestad population (Table 9) may allow a wider range of genotypes to persist, preventing the erosion of genetic variance for seed weight and the rate of seed germination. By contrast, the selective advantage of large seeds (and seedlings) and rapid germination should be great in the Grödby population where plants of $S$. integrifolius experience higher levels of competition from other species (Widén, 1987). Although plants in the Benestad population had a higher rate of seed maturation following hand pollination (Table 2), field data indicate that open-pollinated plants in the sparse Benestad population achieve much lower levels of pollination than plants in the dense Grödby population, a possible reflection of the density-dependent pollination success demonstrated in previous studies of $S$. integrifolius (Widén, 1991b, 1993). The presumably low rate of pollination in the Benestad population probably result in stronger pollinator-mediated selection on floral characters, at least with regard to female fecundity. That the number of ray florets per head and the length of the ligules, two major components of the floral display, had significant heritabilities in the Grödby population and not in the Benestad population is consistent with this hypothesis.

Natural selection is expected to favour plants with a large number of leaves, particularly in competitive habitats. Hence, the presence of additive genetic variance for rosette size in the partly shaded Grödby population contrasts with the idea that selection eliminates heritable variation for characters connected with fitness. It is important to stress that heritabilities measured in non-competitive conditions may not be representative for those expressed in competitive conditions (Mazer \& Schick, 1991). As the Benestad plants occur in a more open habitat, it should be easier for selection to eliminate genetic variance for characters expressed in the greenhouse, explaining the lower heritability for rosette size in this population.

To our knowledge, this is the first study that relates quantitative genetic variation to population size in a rare and threatened plant. Ouborg et al. (1991) found a positive correlation between the amount of phenotypic variation and population size in two declining species in the Netherlands, but did not distinguish between genetic and non-genetic sources of variation. In the present investigation, a small population (Benestad) has a larger number of characters with significant heritabilities than a large population (Grödby), contrasting with the prevailing view that numerically small populations are genetically depleted (Franklin, 1980; Frankel \& Soulé, 1981). Although a correlation between population size and the level of allozyme diversity has been found in some studies (Karron, 1987; van Treuren et al., 1991), it is important to stress 
that most allozymes are assumed to be selectively neutral, making them more susceptible to genetic drift (see Hamrick \& Allard, 1972; and Nevo et al., 1986 for exceptions).

Although selection may account for some of the population differences observed in this study (see above), we cannot exclude genetic drift as a causal factor. Stochastic processes are probably most important in the Benestad population where plants occur in small and isolated patches. Given the relatively large distances between the patches $(10-50 \mathrm{~m})$, crosspollination occurs largely between neighbouring individuals in the same patch, perhaps leading to higher levels of inbreeding in this population. In a parallel study, we have detected a greater decrease in offspring fitness in crosses between neighbouring individuals in the Benestad population than in the Grödby population (B. Widén \& S. Andersson, unpublished data), supporting the idea that the Benestad population is genetically structured with patches of related plants. Moreover, crosses within full-sib families showed greater segregation for chlorophyll-deficient seedlings in the Grödby population than in the Benestad population (Widén \& Andersson, 1993), presumably because inbreeding has been sufficiently strong to eliminate recessive lethal alleles in the latter population. According to some population genetic models (Maruyama, 1972), a subdivided population can maintain higher levels of genetic variation than a panmictic population of the same size, an alternative explanation of the slightly higher heritabilities in the small Benestad population. There is also evidence that enforced inbreeding can release additive genetic variance for traits associated with fitness (Bryant et al., 1986; Lópes-Fanjul \& Villaverde, 1989).

The results from the present study, combined with data from other studies of $S$. integrifolius (Widén 1987, 1993; B. Widén \& S. Andersson, 1993, unpublished data) support the hypothesis that demographic and environmental factors are of more immediate importance than population genetics in determining extinction probabilities (Goodman, 1987a,b; Lande, 1988; Shaffer \& Samson, 1985). When natural populations become fragmented through habitat destruction, it probably takes many generations before inbreeding depression or erosion of genetic variation cause extinction, particularly in long-lived perennials. The fact that some natural populations of $S$. integrifolius in south Sweden have been small during the last century (Andersson, 1944; Nilsson \& Gustafsson, 1977) without detectable erosion of genetic variation (Widén, 1993, this study), indicates that a combination of variable selection and population substructuring could contribute to the preservation of genetic variation for fitness traits in small plant populations.

\section{Acknowledgements}

We thank Azemat Peykani who carried out most of the measurements. Financial support to B. Widén by the Swedish Environmental Protection Agency is acknowledged.

\section{References}

ANDERsson, o. 1944. Bidrag till Skånes flora. 30. Senecio integrifolius. Botaniska Notiser, 1944, 444-458 (in Swedish).

ANTONOVICS, J. 1976. The nature of limits to natural selection. Ann. Missouri. Bot. Gard., 63, 224-247.

AVERY, P. J. AND HILL, W. G. 1977. Variability in genetic parameters among small populations. Genet. Res., 29, 193-213.

BILLINGTON, H. L., MORTIMER, A. M. AND MCNEILly, T. 1988. Divergence and genetic structure in adjacent grass populations. I. Quantitative genetics. Evolution, 42, 1267-1277.

BRYANT, E. H., MCCOMMAS, S. A. AND COMBS, C. M. 1986. The effects of an experimental bottleneck upon quantitative genetic variation in the housefly. Genetics, 114, 1191-1223.

FALCONER, D. S. 1981. Introduction to Quantitative Genetics, 2nd edn. Longman, London, U.K.

FISHER, R. A. 1930. The Genetical Theory of Natural Selection. Oxford University Press, New York.

ENNOS, R. A. 1983. Maintenance of polymorphism in plant populations. Evol. Biol., 16, 129-156.

FRANKEL, O. H. AND SOULÉ, M. E. 1981. Conservation and Evolution. Cambridge University Press, Cambridge.

FRANKLIN, I. R. 1980. Evolutionary change in small populations. In: Soulé, M. E. and Wilcox, B. A. (eds) Conservation Biology: an Evolutionary-Ecological Perspective, Sinauer Associates, Sunderland, MA, pp. 135-149.

GILES, B. E. AND EDWARDS, K. J. R. 1983. Quantitative variation within and between populations of wild barley, Hordeum murinum. Heredity, 51, 325-333.

Goodman, D. 1987a. How do any species persist? Lessons for conservation biology. Conserv. Biol., 1, 59-62.

GOODMAN, D. 1987b. The demography of chance extinction. In: Soulé, M. E. (ed.) Viable Population for Conservation. Cambridge University Press, Cambridge, pp. 11-34.

HAMRICK, L. J. AND GODT, M. J. 1989. Allozyme diversity in plant species. In: Brown, H. D., Clegg, M. T., Kahler, A. L. and Weir, B. S. (eds) Plant Population Genetics, Breeding and Genetic Resources. Sinauer Associates, Sunderland, MA, pp. 43-63.

HAMRICK, L. J. AND ALLARD, R. W. 1972. Microgeographical variation in allozyme frequencies in Avena barbata. Proc. Natl. Acad. Sci., U.S.A ., 69, 2100-2104.

KARRON, J. D. 1987. A comparison of levels of genetic polymorphism and self-compatibility in geographically restricted and widespread plant congeners. Evol. Ecol., 1, 47-58.

KARRON, J. D., LINHART, Y. B., CHAULK, C. A. AND ROBERTSON, C. A. 1988. Genetic structure of populations of geographically restricted and widespread species of Astragalus (Fabaceae). Am. J. Bot., 75, 1114-1119. 
LANDE, R. 1980. Genetic variation and phenotypic evolution during allopatric speciation. Am. Nat., 116, 463-479.

LANDE, R. 1988. Genetics and demography in biological conservation. Science, 241, 1455-1460.

LANDE, R. AND BARROWCLOUGH, G. F. 1987. Effective population size, genetic variation, and their use in population management. In: Soulé, M. E. (ed.) Viable Populations for Conservation. Cambridge University Press, Cambridge, pp. 87-123.

LAWRENCE, M. J. 1984. The genetical analysis of ecological characters. In: Shorrocks, B. (ed.) Evolutionary Ecology. 23rd Symposium of the British Ecological Society, Leeds. Blackwell Scientific Publications, Oxford, pp. 27-62.

LOPES-FANJUL, C. AND VILLAVERDE, A. 1989. Inbreeding increases genetic variance for viability in Drosophila melanogaster. Evolution, 43, 1800-1804.

MARUYAMA, T. 1972. Rate of decrease of genetic variability in a two-dimensional continuous population of finite size. Genetics, 70, 639-651.

MAZER, S. J. AND SCHICK, C. T. 1991. Constancy of population parameters for life history and floral traits in Raphanus sativus L. I. Norms of reaction and the nature of genotype by environment interactions. Heredity, 67, 143-156.

MEAGHER, T. R., ANTONOVICS, J. AND PRIMACK, R. 1978. Experimental ecological genetics in Plantago. III. Genetic variation in relation to survival of Plantago cordata, a rare species. Biol. Conserv., 14, 243-257.

MITCHELL-OLDS, T. 1986. Quantitative genetics of survival and growth in Impatiens capensis. Evolution, 40, 107-117.

MITCHELl-OlDS, T. AND RUTLEDGE, J. J. 1986. Quantitative genetics in natural plant populations: a review of the theory. Am. Nat., 127, 379-402.

MOUSSEAU, T. A. AND ROFF, D. A. 1987. Natural selection and the heritability of fitness components. Heredity, 59, 181-197.

NEVO, E., BEILES, A., KAPLAN, D. GOLDENBERG, E. M., OLSVIGWHITTAKER, L. AND NAVEH, Z. 1986. Natural selection of allozyme polymorphisms, a microsite test revealing ecological differentiation in wild barley. Evolution, 40, 13-20.

NILSSON, Ö. AND GUSTAFSSON, L-A. 1977. Project Linné rapporterar 49-63. Svensk Bot. Tidskr., 71, 205-224 (in Swedish).

NORdEnStam. B. 1977. Senecioneae and Liabeae. Systematic review. In: Heywood, V. H. and Harborne, J. B. (eds) The Biology and Chemistry of the Compositae. Academic Press, London, pp. 799-830.

OUBORG, N. J., VAN TREUREN, R. AND VAN DAMME, J. M. M. 1991. The significance of genetic erosion in the process of extinction II. Morphological variation and fitness components in populations of varying size of Salvia pratensis L. and Scabiosa columbaria L. Oecologia (Berl.), 86, 359-367.

PRICE, T. AND SCHLUTER, D. 1991. On the low heritability of lifehistory traits. Evolution, 45, 853-861.

REGNÉLl, G. 1976. The Benestads backar nature reserve vegetation and flora. Svensk Bot. Tidskr., 70, 17-42 (in Swedish).

ROACH, D. A. 1986. Life history variation in Geranium carolinianum. 1. Covariation between characters at different stages of the life cycle. Am. Nat., 128, 47-57.

ROSE, M. R. AND CHARLESWORTH, B. 1981. Genetics of life history in Drosophila melanogaster. 1. Sib analysis of adult females. Genetics, 97, 173-186.

SAS. 1985. SAS User's Guide: Statistics, Version 5 edn, SAS Institute, Cary, NC.

SCHONEWALD-COX, C. M., CHAMBERS, S. M., MACBRYDE, B. AND THOMAs, w. L. 1983. Genetics and Conservation: A Reference for Managing Wild Animal and Plant Populations. Benjamin Cummings, Menlo Park, CA.

SCHWAEGERLE, K. E. AND LEVIN, D. A. 1991. Quantitative genetics of fitness characters in a wild population of Phlox. Evolution, 45, 169-177.

SHAFFER, M. L. AND SAMSON, F. B. 1985. Population size and extinction: a note on determining critical population sizes. Am. Nat., 125, 144-152.

SMiTh, U. K. 1979. Biological flora of the British Isles, Senecio integrifolius (L.) Clairv. J. Ecol., 67, 1109-1124.

SOULÉ, M. E. AND WILCOX, B. A. (eds) 1980. Conservation Biology. An Evolutionary-Ecological Perspective. Sinauer Associates, Sunderland, MA.

VAN TREUREN, R., BIJLSMA, R., VAN DELDEN, W. AND OUBORG, N. J. 1991. The significance of genetic erosion in the process of extinction. I. Genetic differentiation in Salvia pratensis and Scabiosa columbaria in relation to population size. Heredity, 66, 181-189.

VENABLE, D. L. 1984. Using intra-specific variation to study the ecological significance and evolution of plant lifehistories. In: Dirzo, R. and Sarukhan, J. (eds) Perspectives on Plant Population Ecology. Sinauer Associates, Sunderland, MA, pp. 166-187.

VIA, S. 1984. The quantitative genetics of polyphagy in an insect herbivore. II. Genetic correlations in larval performance within and among host plants. Evolution, 38, 896-905.

VIA, S. AND LANDE, R. 1985. Genotype-environment interaction and the evolution of phenotypic plasticity. Evolution, 39, 505-522.

WALlER, D. M., O'MALLEY, D. M. AND GAWLER, S. C. 1987. Genetic variation in the extreme endemic Pedicularis furbishiae (Scrophulariaceae). Conserv. Biol., 1, 335-340.

WEIS, A. E., HOLlENBACH, H. G. AND ABRAhAMSON, w. G. 1987. Genetic and maternal effects on seedling characters of Solidago altissima (Compositae). Am. J. Bot., 74, 1476-1486.

WIDÉN, B. 1987. Population biology of Senecio integrifolius (Compositae), a rare plant in Sweden. Nord. J. Bot., 7, 687-704.

WIDÉN, B. 1991a. Environmental and genetic influence on phenology and plant size in a perennial herb, Senecio integrifolius. Can. J. Bot., 69, 209-215.

WIDÉN, B. 1991b. Phenotypic selection on flowering phenology in Senecio integrifolius, a perennial herb. Oikos, 61, 205-215.

WIDÉN, B. 1993. Demographic and genetic effects on reproduction as related to population size in a rare, perennial herb, Senecio integrifolius. Biol. J. Linn. Soc., (in press).

WIDÉN, B. AND ANDERsson, s. 1993. Purging of deleterious alleles in a rare plant, Senecio integrifolius. (Submitted).

WINER, B. J. 1971. Statistical Principles in Experimental Design. McGraw-Hill, New York. 